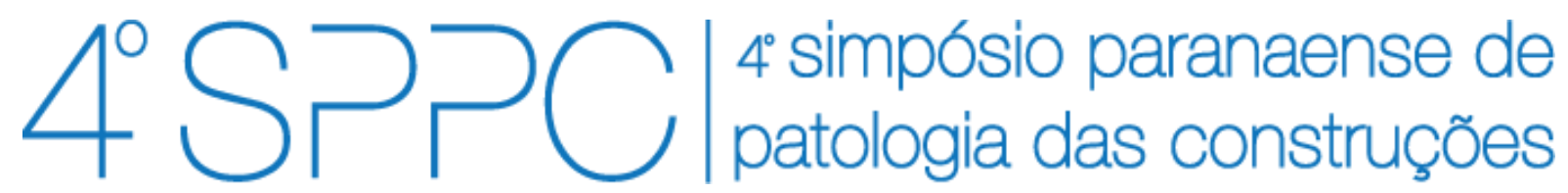

ISSN 2526-7248 artigo n. 4SPPC139, pp. 348-357, 2019

\title{
O potencial da termografia na detecção do aço em estruturas de argamassa armada
}

\author{
Oliveira, Leonardo Covatti ${ }^{1}$; Medeiros, Arthur ${ }^{2}$; Mazer, Wellington ${ }^{3}$; \\ Matoski, Adalberto ${ }^{4}$ \\ ${ }^{1}$ Mestrando, UTFPR, Curitiba, contato@confienge.com \\ 2 Doutor, UTFPR, Curitiba, arthurmedeiros@utfpr.edu.br \\ ${ }^{3}$ Doutor, UTFPR, Curitiba, wmazer@utfpr.edu.br \\ ${ }^{4}$ Doutor, UTFPR, Curitiba, adalberto@utfpr.edu.br
}

\begin{abstract}
Resumo: O estudo de detecção de estruturas e manifestações patológicas por meio de técnicas minimamente invasivas tem crescido no setor da construção civil. Entre as técnicas estão a de mensuração da resistividade do concreto, ultrassom, pacometria, entre outros. Neste artigo, com a intenção de detectar a armadura no inteiro de estruturas de argamassa armada, um ensaio não destrutivo (END), utilizando termografia, foi realizado em corpos de prova idealizados moldados em laboratório. Através de um estresse térmico, gerado por um equipamento de indução eletromagnética, foi fornecido energia para a barra de aço no inteiro dos corpos de prova, que por condução, transferiu energia para a superfície. $O$ aquecimento por indução foi aplicado durante 150s em cada corpo de prova e o gradiente térmico médio aferido na superfície, logo acima da barra metálica, foi de $5^{\circ} \mathrm{C}$. O aço no interior dos corpos de provas fabricados com cimentos CP V-ARI e CP IV foram detectados em 19s e 23s, respectivamente.
\end{abstract}

Palavras-chave: Câmera termal, ensaio não destrutivo, concreto armado, indução eletromagnética, detecção de armadura.

Abstract: The study of detection of structures and pathological manifestations with minimally invasive techniques is increasing in the construction industry. Among these techniques are the measuring the resistivity of concrete, pacometry to name a few. In this paper, in order to detect possible pathologies in the reinforcement of concrete elements, a non-destructive test (NDT), using a thermography, was performed to analyze the position of the carbon steel bars inside small and idealized reinforced concrete specimens molded in laboratory. Through thermal stress generated by an electromagnetic induction equipment, power was supplied to the internal rebars which, by conduction, transferred heat to the surface of concrete specimens. Induction heat was applied during 150s in each specimen and a thermal variation of $5^{\circ} \mathrm{C}$ was recorded on the surface above the metallic elements. After $19 \mathrm{~s}$ and $23 \mathrm{~s}$ it was possible to detect the steel bar inside the specimens made with Brazilian Portland cements CP V-ARI and CP IV, respectively.

Keywords: Thermal camera, non-destructive test, reinforced concrete, electromagnetic induction, reinforcement detection. 
OLIVEIRA, L. C; MEDEIROS, A.; MAZER, W.; MATOSKI, A. O POTENCIAL DA TERMOGRAFIA NA DETECÇÃO DO AÇO EM ESTRUTURAS DE CONCRETO ARMADO. 40 Simpósio Paranaense de Patologia das Construções (40 SPPC), artigo 4SPPC139, pp. 348 - 357, 2019. DOI: 10.4322/2526-7248.057

\section{Introdução}

No Brasil a termografia infravermelha é utilizada na construção civil basicamente para a deteção de umidade, infiltrações ou problemas de desplacamento cerâmico em elementos de vedação. Objetivando uma nova maneira de inspecionar outros elementos construtivos, como estruturas de argamassa armada, e detectar possíveis patologias na construção civil, como falhas de cobrimento e/ou oxidação de armaduras, um método já estudado em outros países foi aplicado neste trabalho para observar como seria o desempenho dos matérias brasileiros com está técnica.

Algumas das técnicas não destrutivas aplicadas atualmente na indústria da construção civil brasileira para aferir o posicionamento de armaduras no interior de elementos estruturais são a pacometria, ultrassom ou raio-x. Já para aferir a potencialidade de um elemento metálico estar oxidado no interior de estruturas de concreto armado, um ensaio minimamente destrutivo denominado potencial de corrosão pode ser aplicado.

Para realizar a detecção, posicionamento e existência de patologias como oxidação de armaduras e umidade em estruturas de concreto armado pode ser utilizando a termografia ativa. Logo, este trabalho tem como objetivo aplicar esta técnica em matérias brasileiro e analisar, em especifico, qual tipo de cimento responderá melhor.

\section{Revisão Bibliográfica}

Esclerometria, ultrassom e termografia são alguns dos ensaios não destrutivos (END) mais utilizados na construção civil. Segundo Al Alam [1], estes métodos possuem materiais bibliográficos e pesquisas teóricas de aplicação prática para detecção de características e manifestações patológicas em construções.

Takeda e Mazer [2] utilizando a técnica de termografia explicam que este tipo de inspeção não destrutiva e não invasiva visa detectar a radiação infravermelha emitida naturalmente, por excitação de uma fonte natural ou artificialmente produzida (ativa), pelos corpos com intensidade proporcional à sua temperatura.

Segundo Silva [3], a termografia é uma técnica não destrutiva simples e rápida que pode ser utilizada para avaliar estruturas construídas. Ao se analisar uma construção com o auxílio de uma câmera termal é possível observar algumas anomalias, como a umidade por infiltração, fugas de água e ar, isolamentos ineficientes e até mesmo aferir o funcionamento de equipamentos instalados em locais de difícil acesso.

Avdelidis, Moropoulou e Theoulakis [4] utilizaram a termografia para inspecionar a elevação de água por capilaridade em pedras porosas. Os resultados obtidos, através do ensaio não destrutivo, foram satisfatórios, pois forneceram informações significativas sobre a umidade em ascensão.

Utilizando as técnicas não destrutivas de termografia e ultrassom Válek et al. [5] inspecionaram paredes construídas com tijolos de argila, arenito e espondilite, danificadas pela umidade. Segundo os autores, os resultados foram satisfatórios quando analisados qualitativamente. Porém, houveram algumas dispersões nos resultados analisados quantitativamente. 
Keo et al. [6] forneceram energia ativa a estruturas de concreto armado através da aplicação de micro-ondas e observaram a reação do compósito através da termografia. Os autores notaram que, na região onde existia uma área maior de aço, houve um aumento de temperatura considerável. Este aumento foi moderado e não foi suficiente para alterar as características do concreto inspecionado.

Também utilizando micro-ondas, Szymanik et al. [7] conseguiram observar o reforço interno em aço de elementos estruturais de concreto armado. O ensaio foi semelhando ao realizados por Keo et al. [6].

Milovanovic, et al. [8] usando a metodologia de termografia infravermelha ativa, fornecendo energia ao sistema através de um meio artificial, conseguiram detectar e quantificar com precisão de $90 \%$ os defeitos em estruturas de concreto armado.

Fornecendo energia ativa, através de indução eletromagnética a corpos de provas de concreto armado, Kobayashi e Banthia [9] conseguiram detectar as armaduras de diversos diâmetros em diferentes profundidades. A detecção foi possível pelo uso de uma câmera termal, como mostrado na Figura 1.

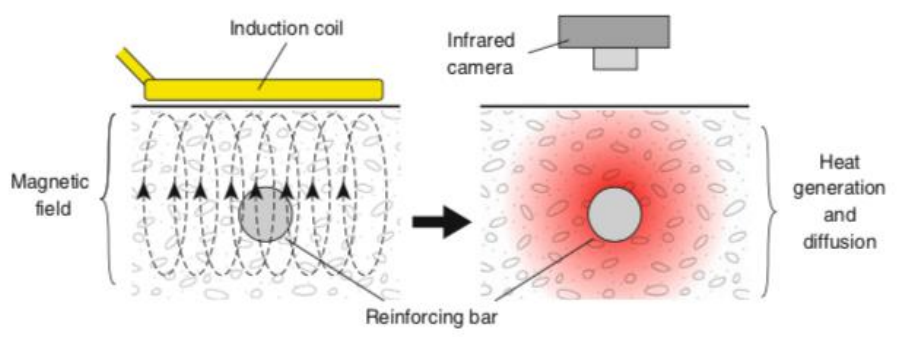

Figura 1: Combinação de aquecimento por indução eletromagnética e termografia infravermelha para a detecção de corrosão em armaduras de concreto armado Fonte: Kobayashi e Banthia [9]

Também foi possível localizar as oxidações de armaduras, induzidas nas barras através de um ensaio eletrolítico com corrente constante, onde os corpos de provas estavam em contato com uma solução de $\mathrm{NaCl}$ por um período específico. O princípio para se conseguir detectar os pontos de oxidação das armaduras dentro do concreto é que a difusão do calor da barra de aço para a superfície será dificultada devido a baixa condutividade térmica do óxido (Fig. 2).

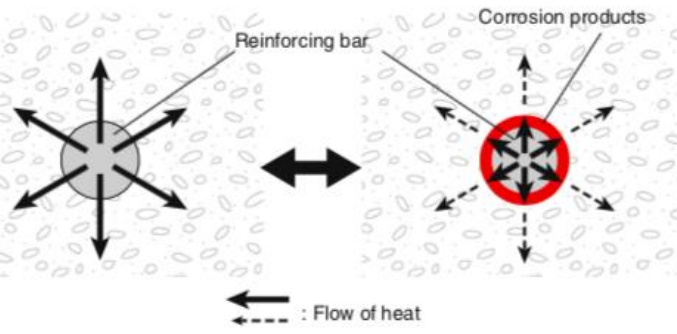

Figura 2: Efeito devido a baixa condutividade térmica dos óxidos na armadura de um elemento de concreto armado.

Fonte: Kobayashi e Banthia [9] 
Os corpos de prova idealizados por Kobayashi e Banthia [9] são detalhados na Figura 3. Por fim, a técnica de detecção de armadura em corpos de prova obteve melhores resultados quando o diâmetro da barra era maior ou a profundidade do cobrimento de concreto era menor.

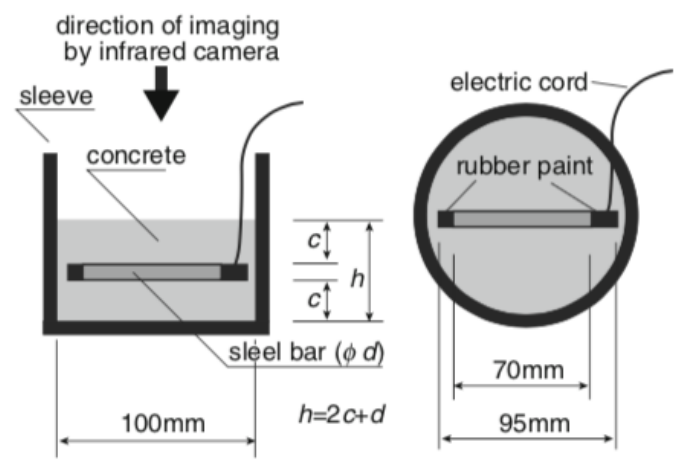

Figura 3: Detalhamento dos corpos de prova de concreto armado idealizados Fonte: Kobayashi e Banthia [9]

\section{Materiais e métodos}

\subsection{Corpos de prova de argamassa armada}

Seguindo a metodologia proposta por Kobayashi e Banthia [9], foram produzidos doze corpos de provas, sendo seis moldados utilizando cimento CP V-ARI e o demais confeccionados em CP IV. Cada corpo de prova cilíndrico possuí diâmetro de $100 \mathrm{~mm}$ e $26,3 \mathrm{~mm}$ de altura. A armadura utilizada tem um diâmetro nominal de $6,3 \mathrm{~mm}$ e comprimento de $70 \mathrm{~mm}$. O cobrimento estipulado foi de $10 \mathrm{~mm}$, similar ao utilizado na metodologia de Kobayashi e Banthia [9]. O traço utilizado está discriminado na Tabela 1. Após um dia, os corpos de prova foram desmoldados, aferidas as dimensões e colocados em cura úmida por 28 dias.

Tabela 1: Traço argamassa para 6 corpos de prova

\begin{tabular}{cc}
\hline Material & [gramas] \\
\hline Água & 396 \\
Cimento & 720 \\
Areia & 2200 \\
\hline
\end{tabular}

O traço 1:3 na confecção dos corpos de prova está em acordo com a ABNT NBR 7215:1996. O fator água/cimento de 0,55 é similar ao utilizado por Kobayashi e Banthia [9].

\subsection{Aquecedor por indução e câmera termal}

Similar com a metodologia de Kobayashi e Banthia [9], foi utilizado um fogão de indução, que possui uma bobina de indução diametral e potência de $1400 \mathrm{~W}$. Para registrar os termogramas foi usada uma câmera termal, modelo FLIR E-60, com 
OLIVEIRA, L. C; MEDEIROS, A.; MAZER, W.; MATOSKI, A. O POTENCIAL DA TERMOGRAFIA NA DETECÇÃO DO AÇO EM ESTRUTURAS DE CONCRETO ARMADO. $4^{\circ}$ Simpósio Paranaense de Patologia das Construções (40 SPPC), artigo 4SPPC139, pp. 348 - 357, 2019. DOI: $10.4322 / 2526-7248.057$

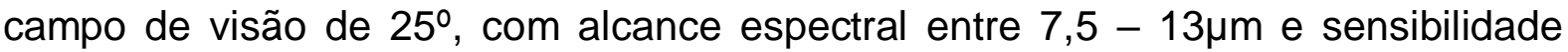
inferior a $0,05^{\circ} \mathrm{C}$.

\subsection{Aquecimento de referência de uma barra nua}

Com o intuito de aferir se a energia fornecida ao sistema era constante e se a distância de $10 \mathrm{~mm}$ da superfície do indutor eletromagnético seria o suficiente para que houvesse o contato do campo eletromagnético, uma barra nua foi submetida a aquecimento (Fig. 4a). Foram utilizados espaçadores de madeira com altura de $10 \mathrm{~mm}$ nas extremidades da barra para simular o cobrimento padronizado. O ensaio teve duração de 120 s e a temperatura superficial da barra foi monitorada antes e durante o ensaio, com o auxilio da FLIR E-60.

\subsection{Aquecimento dos corpos de prova por indução eletromagnética}

Os corpos de prova de argamassa armada foram aquecidos através de indução eletromagnética por 150s (Fig. 4b), similar ao realizado por Kobayashi e Banthia [9]. A temperatura superficial do corpo de prova em teste foi monitorada antes e durante o ensaio, utilizando a câmera termal FLIR E-60. As diferenças de temperatura detectadas ocorreram nas armaduras inseridas no interior dos corpos de prova.

a)

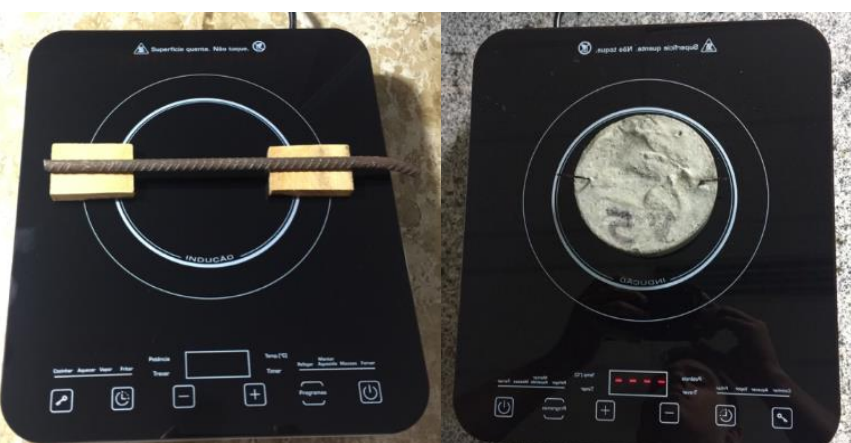

b)

Figura 4: a) Aquecimento de referência da barra nua; b) Aquecimento do corpo de prova armado

\section{Resultados e discussões}

\subsection{Aquecimento de referência de uma barra nua}

O desenvolvimento da temperatura na barra de aço não oxidada, com diâmetro de $6,3 \mathrm{~mm}$, e distanciada da superfície do indutor eletromagnético em $10 \mathrm{~mm}$ é apresentado na Figura 5. Os testes foram repetidos por 4 vezes com a mesma barra e condições (Fig. 5a). O ensaio teve uma reprodução semelhante ao realizado no estudo de Kobayashi e Banthia [9]. Foi constatado que a energia é fornecida ao sistema de maneira constante e que o cobrimento padronizado não afeta nos resultados. Os valores médios obtidos são apresentados na Figura 5b. Através dos resultados, foi ajustada uma expressão referente ao aumento da temperatura (Eq. 1) com $R^{2}=0,9965$.

$$
Y=-0,0541 x^{2}+5,6317 x+22,613
$$



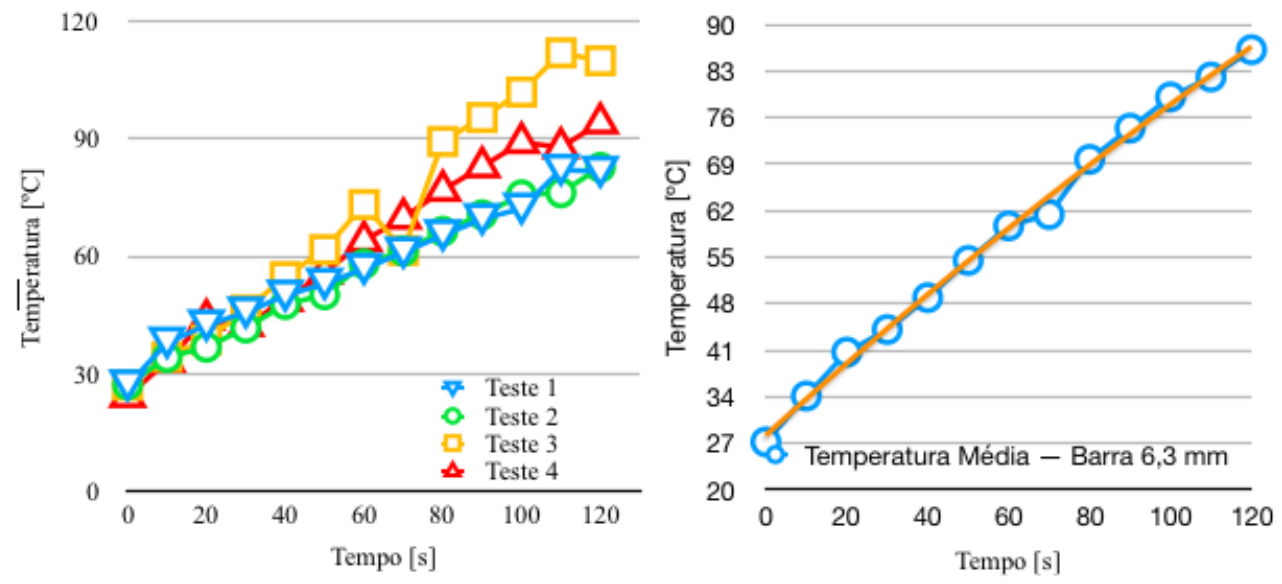

Figura 5: a) Temperatura registrada em quatro ensaios diferentes na barra nua;

b) Temperatura média registrada devido aquecimento por indução na barra nua

\subsection{Aquecimento dos corpos de prova por indução eletromagnética}

As imagens infravermelhas foram capturadas durante um período de aquecimento constante de 150 segundos com uma potencia constante de 1400 watts, similar aos parâmetros utilizados por Kobayashi e Banthia [9]. Os termogramas apresentados na Figura 6 são referentes a um dos seis ensaios realizados com corpos de provas utilizando o cimento Portland CP V-ARI, no qual as imagens foram realizadas em um intervalo de 25 segundos.

$\mathrm{Na}$ Figura 7a é possível observar os valores das temperaturas registradas na superfície dos corpos de prova moldados com cimento Portland CP V-ARI. Com o intuito de manter um padrão no mensuramento das temperaturas, foi optado em aferir os valores no centro dos corpos de prova. Os valores foram registrados em um intervalo de 10 segundos. Na Figura 7b, os valores médios do desenvolvimento de temperatura ao longo dos 150 segundos nos 6 testes estão expressados. Foi possível ajustar uma parábola (linha laranja na Figura 7b), obtendo uma equação polinomial de segundo grau (Equação 2) com um $\mathrm{R}^{2}$ de 0,9865.
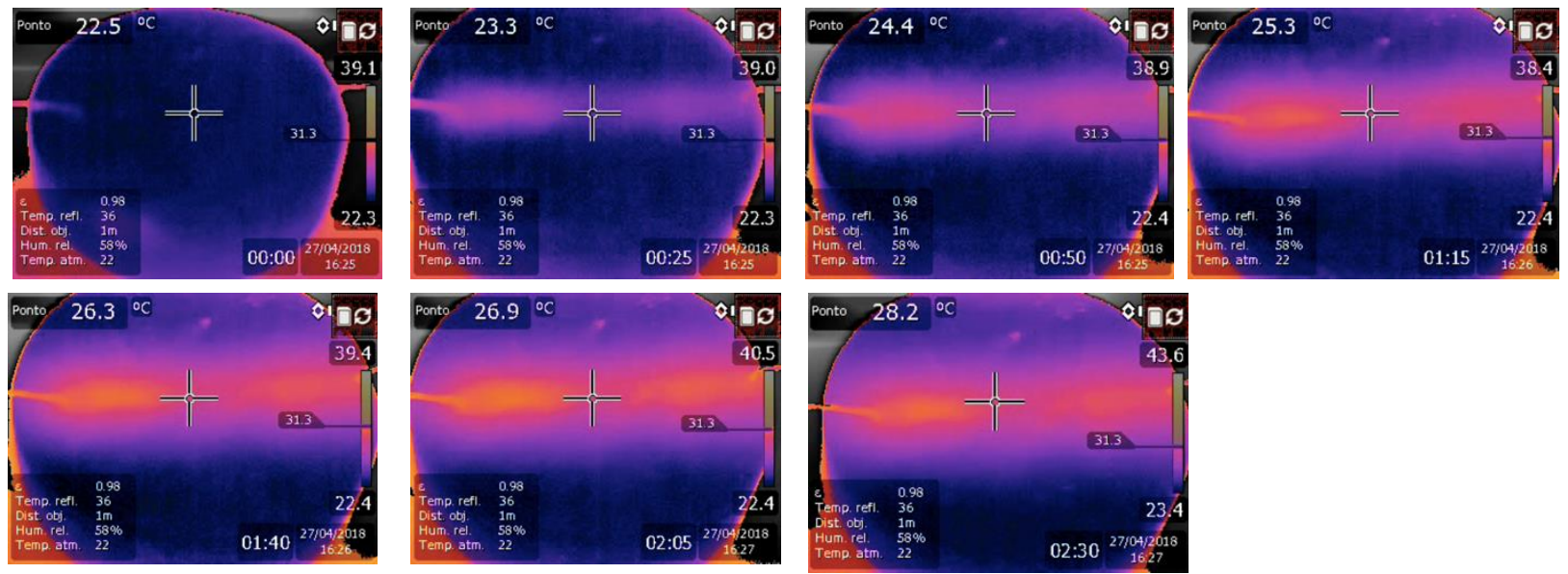

Figura 6: a) Termogramas registrados em um intervalo de 25 segundos durante 0 teste de aquecimento por indução eletromagnética (CP V-ARI)

$$
Y=-0,0132 x^{2}+0,5665 x+22,091
$$


OLIVEIRA, L. C; MEDEIROS, A.; MAZER, W.; MATOSKI, A. O POTENCIAL DA TERMOGRAFIA NA DETECÇÃO DO AÇO EM ESTRUTURAS DE CONCRETO ARMADO. 40 Simpósio Paranaense de Patologia das Construções (40 SPPC), artigo 4SPPC139, pp. $348-357$, 2019. DOI: $10.4322 / 2526-7248.057$
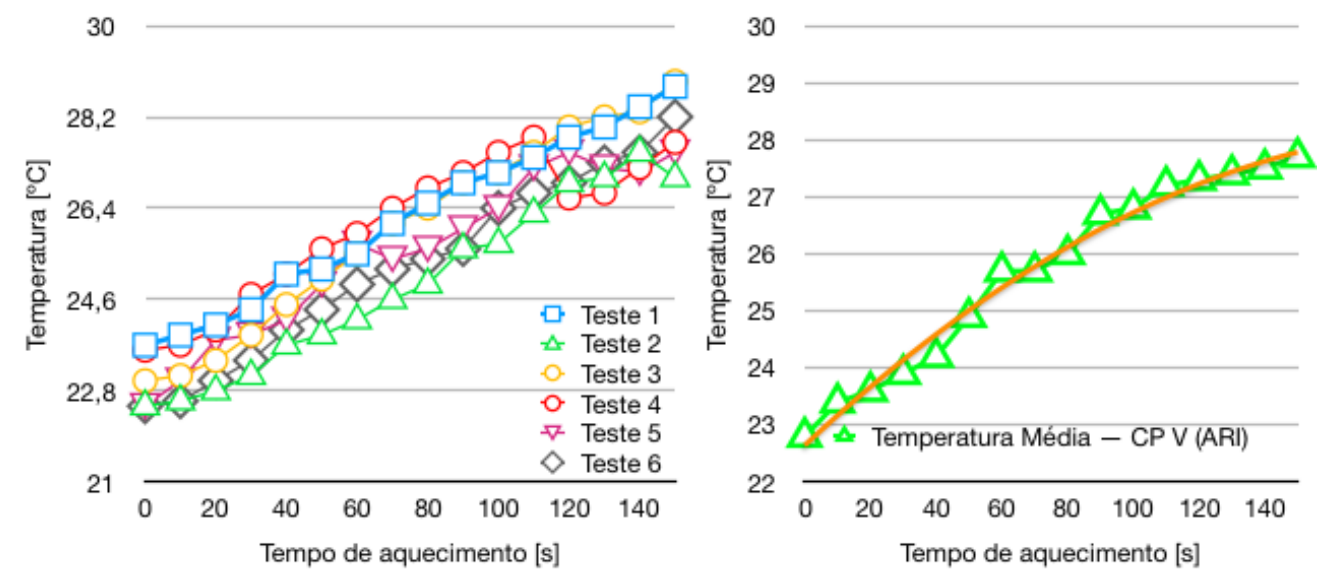

Figura 7: a) Temperatura registrada na superfície dos corpos de provas CP V-ARI aquecidos por indução eletromagnética (AIE); b) Temperatura média registrada na superfície de todos os corpos de prova de CP V-ARI durante AIE

Quando analisados os seis testes foi verificado que o tempo médio para que a barra de metal do interior dos corpos de prova de CP V-ARI sejam visíveis, quando submetidos a um estresse térmico por indução eletromagnética a uma potencia constante de 1400 Watts, foi de 19 segundos. Na Figura 8 é mostrado o exato momento em que foi possível detectar as armaduras em cada um dois 6 ensaios.
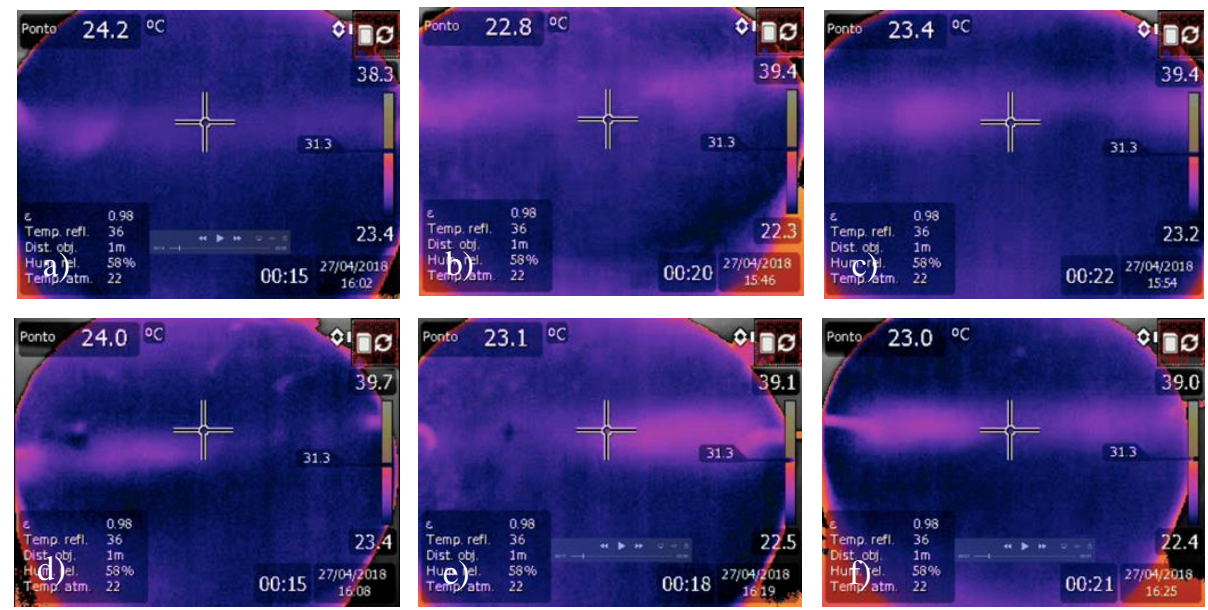

Figura 8: a) Momento em que foi possível detectar a presença de armadura de $6,3 \mathrm{~mm}$ de diâmetro com a câmera termal quando fornecido energia aos concretos por indução eletromagnética; Copos de provas testados são referenciados como: a) teste 1, (b) teste 2, (c) teste 3, (d) teste 4, (e) teste 5 e (f) teste 6.

$\mathrm{Na}$ Figura 9a os valores das superfícies dos corpos de provas moldados com CP IV são apresentados. Com o intuito de manter um padrão no mensuramento das temperaturas, foi optado em utilizar o mesmo método aplicado em CP V-ARI. Na Figura 9b, os valores médios do desenvolvimento de temperatura são expressados. 
OLIVEIRA, L. C; MEDEIROS, A.; MAZER, W.; MATOSKI, A. O POTENCIAL DA TERMOGRAFIA NA DETECÇÃO DO AÇO EM ESTRUTURAS DE CONCRETO ARMADO. $4^{\circ}$ Simpósio Paranaense de Patologia das Construções (40 SPPC), artigo 4SPPC139, pp. $348-357$, 2019. DOI: $10.4322 / 2526-7248.057$

Foi possível ajustar uma parábola (linha laranja na Figura 9b), obtendo uma equação polinomial de segundo grau (Equação 3) com um $\mathrm{R}^{2}$ de 0,9919.

$$
Y=-0,0029 x^{2}+0,2849 x+22,556
$$
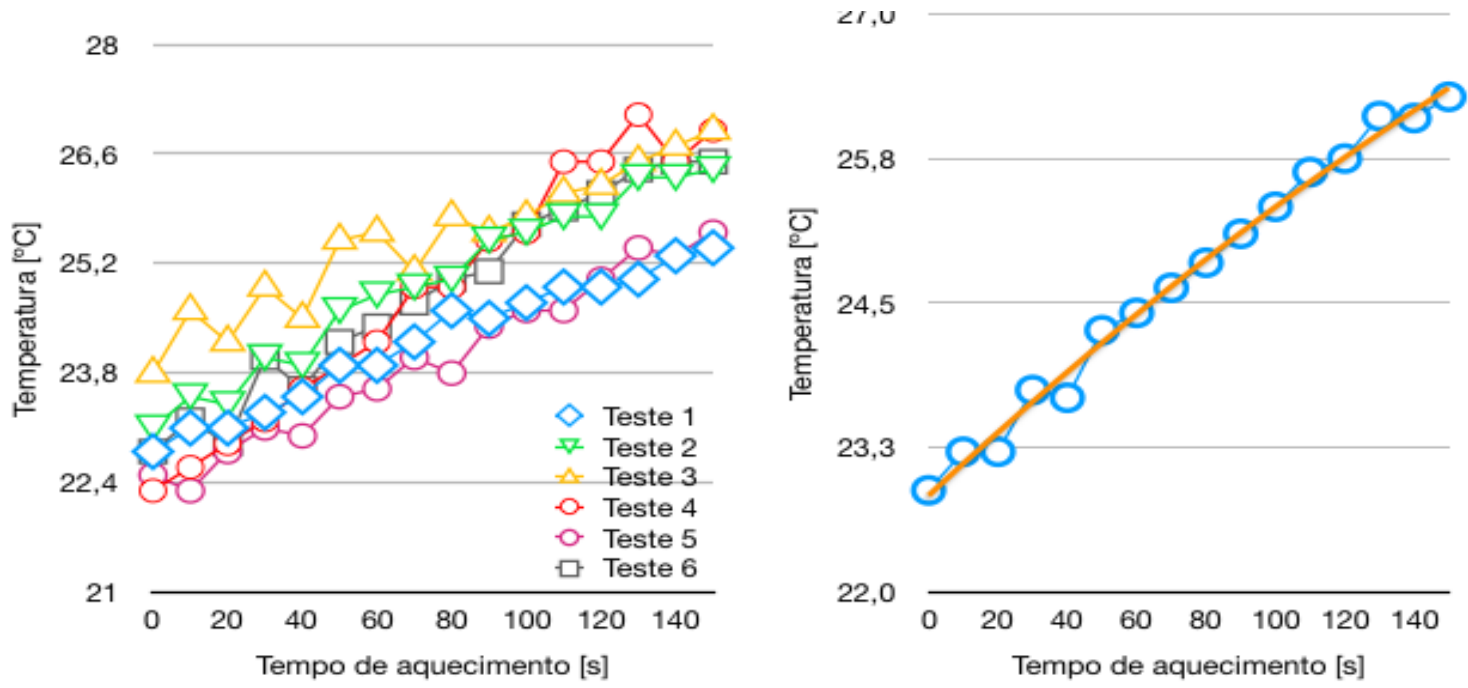

Figura 9: a) Temperatura registrada na superfície dos corpos de provas CP IV aquecidos por indução eletromagnética (AIE); b) Temperatura média registrada na superfície de todos os concretos de CP IV durante AIE

Analisando os resultados obtidos nos corpos de provas moldados com CP IV, a temperatura média para que o metal no interior das argamassas se tornasse visível, foi de 23 segundos. As imagens do momento em que foi notada a aparição da armadura estão apresentadas na Figura 10.
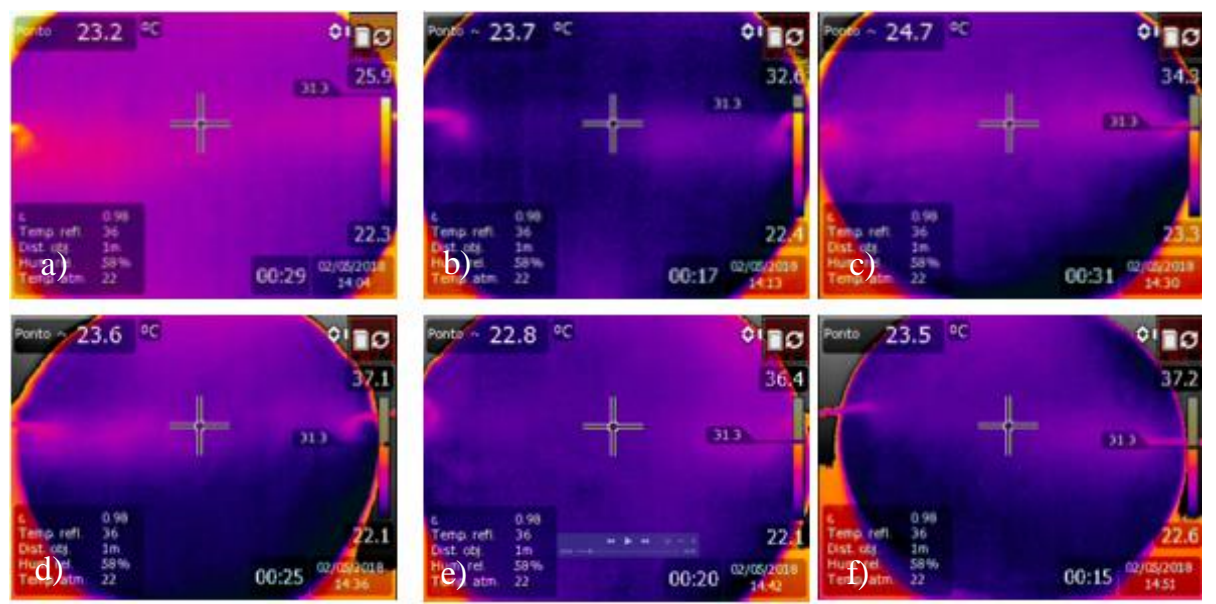

Figura 10: a) Momento em que foi possível detectar a presença de armadura de $6,3 \mathrm{~mm}$ de diâmetro com a câmera termal quando fornecido energia aos concretos por indução eletromagnética; Copos de provas (CP IV) testados são referenciados como: a) teste 1, (b) teste 2, (c) teste 3, (d) teste 4, (e) teste 5 e (f) teste 6. 
OLIVEIRA, L. C; MEDEIROS, A.; MAZER, W.; MATOSKI, A. O POTENCIAL DA TERMOGRAFIA NA DETECÇÃO DO AÇO EM ESTRUTURAS DE CONCRETO ARMADO. 40 Simpósio Paranaense de Patologia das Construções (40 SPPC), artigo 4SPPC139, pp. $348-357$, 2019. DOI: $10.4322 / 2526-7248.057$

\subsection{Comparação entre as temperaturas superficiais da barra nua e corpos de prova}

Quando comparado a evolução das temperaturas na barra nua e as desenvolvidas na superfície dos corpos de provas (Fig. 11), é possível perceber um elevado gradiente de temperatura entre os dois. Isso ocorre devido a argamassa ser um mau condutor de calor $(1,15 \mathrm{~W} / \mathrm{m} . \mathrm{K})$ e possuir uma condutividade térmica muito menor que o aço $(55 \mathrm{~W} / \mathrm{m} . \mathrm{K})$, o que causa um atraso na transmissão de energia para o lado de fora do corpo por condução.

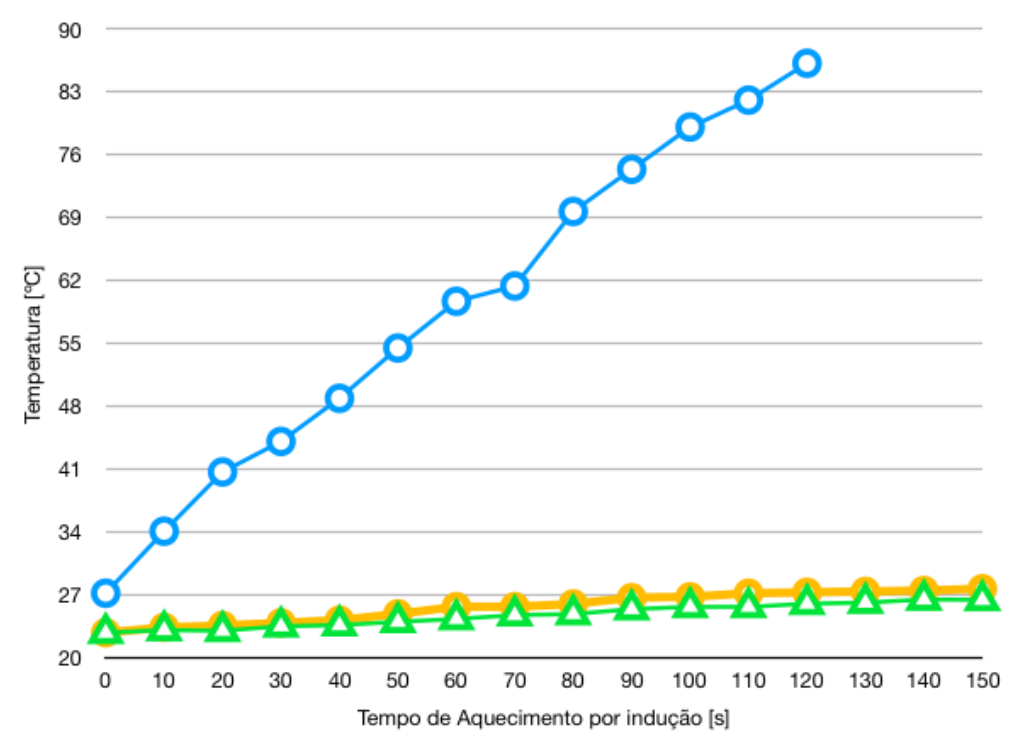

Figura 11: Comparação entre as médias das temperaturas aferidas na superfície dos corpos de prova e barra nua

\section{Conclusões}

Um método não destrutivo, a termografia infravermelha, foi utilizado para detectar barras de aço no interior de estruturas de argamassa armada através de um estresse térmico. Os resultados obtidos foram comparados entre a evolução de temperatura de uma barra nua e corpos de provas, assim como a possibilidade de identificar a posição do reforço metálico dentro dos corpos de provas e o tempo necessário para localiza-los.

Uma diferença considerável foi observada no desenvolvimento da temperatura entre uma barra de aço exposta e a temperatura registrada na superfície dos corpos de prova de argamassa. Essa diferencia é devido as características dos materiais, visto que a condutividade térmica do aço é maior que a da argamassa.

Foi possível identificar o elemento metálico no interior dos corpos de prova, quando submetidos a indução eletromagnética. $O$ tempo médio para observar o aço, com o auxilio da câmera termal, foi de aproximadamente 19 segundos para os corpos de prova moldados com CP V-ARI e 23 segundos para os moldados em CP IV. A diferença observada mostra que estruturas de argamassa armada projetadas com 0 primeiro tipo de cimento tem a probabilidade de responder melhor do que as estruturas dimensionados com o segundo tipo de aglomerante. 
OLIVEIRA, L. C; MEDEIROS, A.; MAZER, W.; MATOSKI, A. O POTENCIAL DA TERMOGRAFIA NA DETECÇÃO DO AÇO EM ESTRUTURAS DE CONCRETO ARMADO. 40 Simpósio Paranaense de Patologia das Construções (40 SPPC), artigo 4SPPC139, pp. 348 - 357, 2019. DOI: $10.4322 / 2526-7248.057$

$\mathrm{O}$ estudo supõem que os corpos de provas moldados com CP V-ARI necessitariam de menos energia ativa (eletromagnética) para que fosse possível a detecção das barras de aço internas ou localizar manifestações patológicas abaixo da superfície da estrutura de argamassa armada.

Não foram realizadas comparações com outros trabalhos visto que este é o primeiro estudo realizado no Brasil. Já artigos realizados no exterior abordando o mesmo tema usam matérias diferentes, fazendo com que a comparação fique invalidada.

\section{Referências}

[1] AL ALAM, F. W. Potencialidade da termografia na detecção de manifestações patológicas associadas à umidade acidental. 2016. Dissertação (Mestrado em Arquitetura e Urbanismo) - Programa de Pós-Graduação em Arquitetura e Urbanismo, UFPel, Pelotas.

[2] O. T. Takeda, W. Mazer (2018), "Potencial da análise termográfica para avaliar manifestações patológicas em sistemas de revestimentos de fachadas", Revista ALCONPAT, 8 (1), pp. 38 - 50, DOI: http://dx.doi.org/10.21041/ra.v8i1.181

[3] SILVA, D. D. S. Diagnóstico de patologias em fachadas utilizando termografia. 2012. Dissertação de mestrado em Engenharia Civil. Faculdade de Engenharia, Universidade do Porto, Porto.

[4] AVDELIDIS, N.P., MOROPOULOU, A., THEOULAKIS, P. 2003. "Detection of water deposits and movement in porous materials by infrared imaging" . Infrared Physics and Technology, 44(3): 183-190.

[5] VÁLEK, J., KRUSCHWITZ, S., WOSTMANN, J., KIND, T., VALACH, J., KOPP, C, LESAK, J. Nondestructive investigation of wet building material: Mustimethodical approach. 2010, Pages 462-472. Journal of Performance of Constructed Facilities, Volume 24, Issue 5. Prague, Czech Republic.

[6] KEO, S.A., BRACHELET, F., BREABAN, F., DEFER, D., Steel detection in reinforced concrete wall by microwave infrared thermography. 2014, Pages 172177. France,. NDT and E International, Volume 62,.

[7] SZYMANIK, B., FRANKOWSKI, P.K., CHADY, T., CHELLIAH, C.R.A.J. Detection and inspection of steel bars in reinforced concrete structures using active infrared thermography with microwave excitation and eddy current sensors. 2016, Article number 234. Sensors (Switzerland), Volume 16, Issue 2. Poland and India.

[8] MILOYANOVIC, B., PECUR, I. B., STIMER, N. The methodology for quantification in concrete using IR thermography. 2017, Pages 573-582. Journal of Civil Engineering and Management, Volume 23, Issue 5. Croatia.

[9] KOBAYASHI, K., BANTHIA, N. Corrosion detection in reinforced concrete using induction heating and infrared thermography. 2011, Pages 25-35. Journal of Civil Structural Health Monitoring, Volume 1. Canadá. 